\title{
UPALA: PAISAJES RECONSTRUIDOS POR SUS ANTIGUOS INMIGRANTES
}

\section{UPALA: HISTORICAL RECONSTRUCTION OF ITS LANDSCAPE BY ANCIENT SETTLEMENTS}

\author{
Gertrud Peters Solórzano*
}

\begin{abstract}
Resumen: Este artículo reconstruye el diverso paisaje del cantón de Upala, Costa Rica, por medio de sus antiguos pobladores de la primera mitad del siglo XX. La historia del paisaje nos la relatan los autores de las autobiografías campesinas que vivieron en ese territorio, algunos costarricenses otros nicaragüenses. El paisaje histórico es interpretado como una totalidad, uniendo variables físicas, así como sociales y culturales. Cuatro son los aspectos analizados: la integración de la tierra y la población alrededor del recurso acuático, la colonización agrícola, las redes sociales y la migración nacional y nicaragüense y la población fronteriza norte e identidad territorial.
\end{abstract}

Palabras clave: colonización; paisaje; asentamiento; clase campesina; recursos hídricos; fronteras; Upala; Costa Rica; historia.

Abstract: This article aims the diverse landscape of Upala in the first half of the century, which was developed by the settlers of that place. For that reason, this research incorporates pieces of the autobiographies of the farmers, both Costa Ricans and Nicaraguans, who describe the history of the space environment. Furthermore, factors, such as the physical geography, social environment and cultural background, are characteristics considered to study the historical landscape as a whole. Moreover, the reader can appreciate a detailed analysis of four aspects: 1) the settlements and the use of natural resources; 2) Upala's first

Fecha de recepción: 01/06/2018 - Fecha de aceptación: 01/07/2018

* Costarricense. Graduada en Historia por la Universidad de Costa Rica (UCR) y en Administración de Empresas por la National University San Diego, California, sede de Costa Rica. Con experiencia en la historia económica de Costa Rica, en especial en la historia agroecológica y cafetalera, la historia empresarial, la inversión extranjera y los grupos de poder económico. Correo electrónico: petersgertrud.cr@gmail.com 
agriculture production; 3) the migration and social relations patterns of Costa Ricans and Nicaraguans and; 4) the regional identity of this population.

Keywords: Colonization; Landscape; Settlement; Peasantry; Water Resources; Boundaries; Upala; Costa Rica; History.

\section{Introducción}

La reconstrucción del diverso paisaje de Upala que lograron los antiguos pobladores es la base de este trabajo que forma parte de una investigación cuyo objetivo general fue analizar el paisaje histórico de este territorio como una totalidad, donde no se consideraron los elementos físicos como aspectos aislados de los elementos socioculturales y viceversa. El proceso de colonización, de producción agropecuaria y extractiva en la zona se abarcó también a partir del enfoque de la geografía histórica. En este sentido, ambos componentes de esa disciplina serán complementarios e interdependientes buscando la interacción entre dos sistemas: el natural y el social. ${ }^{1}$

\section{Aproximación teórico-explicativa y el uso de fuentes histórico-geográficas}

Por medio de la historia del paisaje se podrá distinguir la manera cómo el ser humano -o su colectivo- ha interpretado su espacio, qué uso se le ha dado a este y cómo se ha vinculado a su entorno de acuerdo también con su historicidad. Para la recuperación del paisaje por medio de sus pobladores, se tomó como fuente histórica las autobiografías campesinas, investigación y publicación de la Escuela de Planificación y Promoción Social de la Universidad Nacional de Costa Rica. ${ }^{2}$ Esta documentación se logró recolectar mediante un concurso nacional realizado en 1977 y donde se recopilaron 802 escritos, un 70\% de hombres y el resto de mujeres. ${ }^{3}$ Para el caso de Upala se han recolectado dieciséis documentos de campesinos ambos sexos que tenían una edad entre los 27 y los 78 años, con énfasis en mayores de cuarenta años. Aunque son experiencias individuales, se pueden observar

1 Este artículo fue parte del proyecto "Colonización y producción agropecuaria en la zona fronteriza norte de Costa Rica: 1950-2010. I fase. Estudio de caso: Upala” (Escuela de Historia, UNA: 2013-2014). Margarita Torres Hernández y Gertrud Peters Solórzano fueron coordinadoras e investigadoras de esta fase del proyecto.

2 Un agradecimiento especial a la Br. Gineth Rivera por su asistencia en la investigación y al Lic. Óscar Núñez por el diseño de mapas históricos de forma ad honórem.

3 Luisa Goncalves G., "Una contribución al análisis de las autobiografías campesinas", ABRA. Revista de la Facultad de Ciencias Sociales de la Universidad Nacional (Costa Rica) 1, n. 1 (1980): 81-103, URL: http://www.revistas.una.ac.cr/index.php/abra/article/view/4727. 
algunas conciencias colectivas que le dan sentido y pertenencia a su terruño. Como fuente histórica, se ha afirmado que:

\begin{abstract}
"Este concurso se constituyó como elemento de fundamental importancia para el país, por las posibilidades de conocer, "sobre la vida del campesino costarricense, sobre el origen y desarrollo de sus pueblos, de sus costumbres, creencias, ideología, organización social del trabajador, de los problemas en que se han visto inmersos -económicos, políticos, sociales- para poder, a través de estos, rescatar aspectos generales del desarrollo histórico y económico de nuestra sociedad ... informaciones dadas directamente por los parceleros, esquilmeros, precaristas, jornaleros, pequeños propietarios, obreros agrícolas, quienes han sido los verdaderos protagonistas de los procesos de colonización y desarrollo del agro". ${ }^{4}$
\end{abstract}

La conciencia de estas personas se inicia generalmente con la niñez y la supervivencia en zonas tan alejadas como el caso de Nicaragua o regiones marginales del campo costarricense. De esta manera, tanto migrantes nacionales, así como nicaragüenses quienes ingresaron al país por medio de las redes sociales $\mathrm{y}$ familiares o independientemente pero siempre buscando trabajo o un pedazo de tierra para sembrar y mantener a la familia. ${ }^{5}$ Estos hombres y mujeres nos relatan su relación con el medio geográfico, con la familia, los vecinos y los retos de aquella naturaleza agreste: “...cuando llegue a Upala solo unas cuatro casas habían, la Iglesia era un rancho viejo de paja", la comunicación con los otros pueblos de Costa Rica eran escasa o prácticamente nula. ${ }^{6}$

Por otro lado, será también importante la interpretación simbólica que los habitantes le dan al entorno, a través de distintivos que reúnen a la cultura y a la naturaleza. En nuestro caso, se buscaría comprender la interpretación que el hombre en sociedad les ha otorgado a los distintos paisajes, enfocado hacia las lógicas en la permanente transformación de estos. Incluyendo aspectos geográficos, históricos, productivos, poblacionales y algunos componentes culturales, que denoten la relación de los sujetos con su entorno a través de la identidad del paisaje.

\title{
Elementos en la creación de Upala como ente geográfico e histórico
}

El cantón de Upala, por un lado, forma parte de la frontera norte de Costa Rica y tiene características que comparte con la región Chorotega -Pacífico Norte-, así como de la región Huetar Norte, y por otro, existen diferencias en sus componentes agroecológicos y de colonización demográfica. Antes de que Upala se

$4 \quad$ Ibid, 82.

5 Las citas textuales de las autobiografías han sido transcritas manteniendo siempre la redacción y la ortografía original, solo en algunos casos la corrección se ha realizado para una mejor comprensión de los lectores. Se escribirá A.C. como abreviatura de autobiografías campesinas. Todos los campesinos que enviaron la información no pusieron su nombre completo sino las siglas.

6 B.U., A.C. Tomo XVI, 1977: 148. 
convirtiera en cantón en 1970, la óptica hacia esas zonas era de un área deshabitada y de posible colonización para la población blanca en Costa Rica. Los territorios formados por la región norte fronteriza eran llamados las llanuras de los guatusos, se hacía mención cotidianamente de la ruta fluvial del río Frío, del Sarapiquí y otros que desembocaban al río San Juan. ${ }^{7}$ Upala perteneció a la provincia de Alajuela, cantón de Grecia, desde tiempos atrás y hoy tiene sus límites al oeste y sur con Guanacaste, al norte con Nicaragua y al este y al sur con otros cantones de la misma provincia, como se puede observar en el siguiente mapa:

\section{Mapa 1 \\ Ubicación del cantón de Upala en la división territorial administrativa de Costa Rica (1973)}

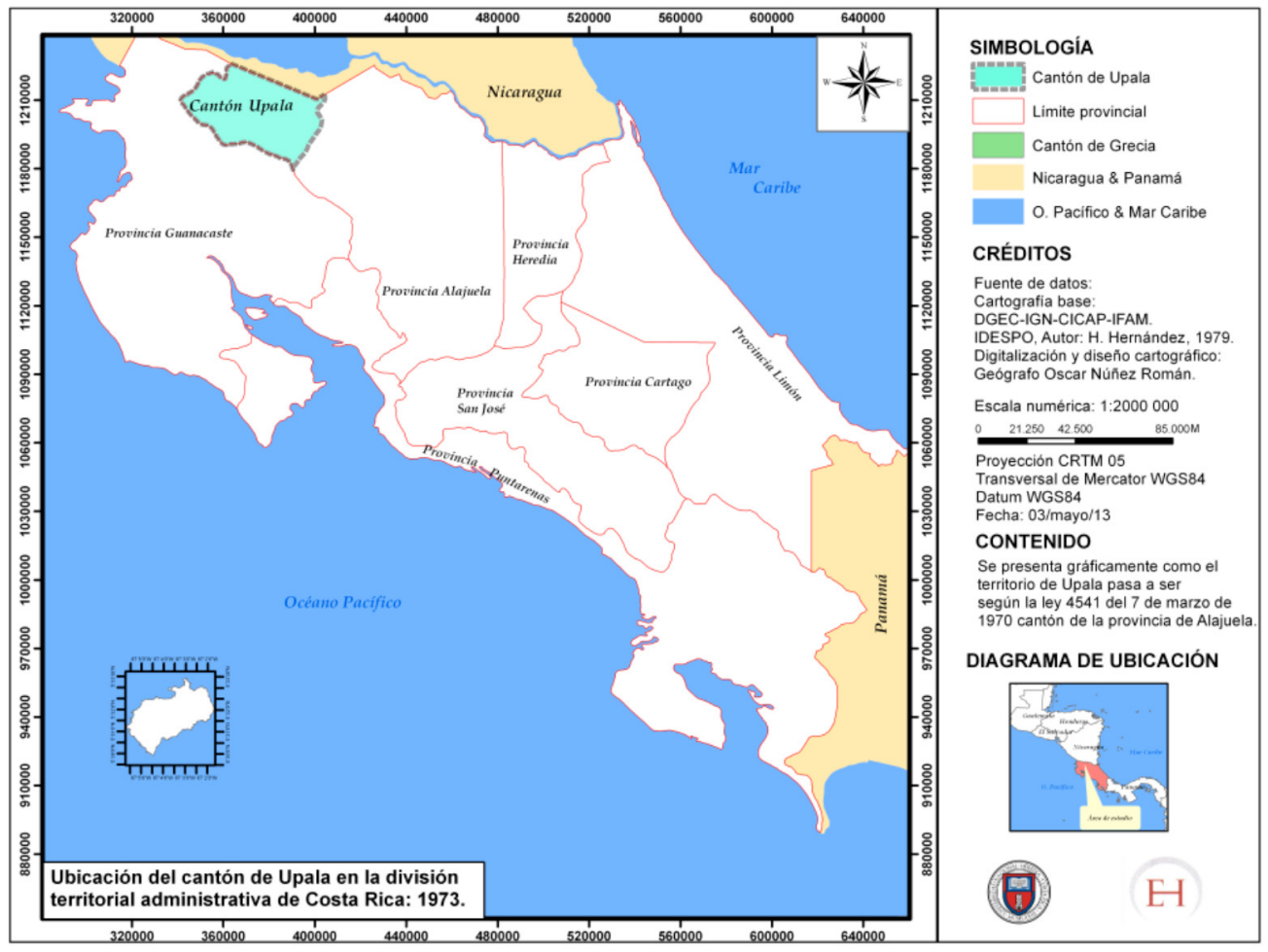

Fuente: Margarita Torres Hernández y Gertrud Peters Solórzano (coords.), “Colonización y producción agropecuaria en la zona fronteriza norte de Costa Rica: 1950-2010. I fase. Estudio de caso: Upala" (Escuela de Historia, UNA: 2013-2014).

7 Ref. a la ponencia Margarita Torres Hernández y Gertrud Peters Solórzano, "El paisaje múltiple del cantón de Upala, Costa Rica. Estudio de una zona fronteriza norte (1880-2012)", II Congreso de la Asociación de Historia Económica del Caribe (Santo Domingo, República Dominicana, junio de 2013). 
Era una frontera agrícola abierta para los planes de desarrollo agrario del Estado costarricense. Así, la Ley No 4.541 del 17 de marzo de 1970 erigió a Upala como cantón número trece de la provincia de Alajuela y se le otorgó el título de Villa a la población de Upala, cabecera del cantón.

Upala posee una extensión de 158.000 hectáreas con una amplia y diversa conformación del paisaje histórico. El territorio de Upala quedó dividido en seis distritos: Upala, Aguas Claras, San José, Bijagua, Las Delicias y Dos Ríos que se encuentran en dos tipos de zonas distintas: la zona baja o las llanuras y la zona alta. ${ }^{8}$ La zona baja tiene una altitud entre los 70 a 100 metros sobre el nivel del mar, con topografía plana y áreas inundadas, posee ríos navegables y áreas boscosas junto con explotación agropecuaria. En la zona alta existen dos valles: el de Aguas Claras y el de Bijagua. Tienen una topografía más o menos ondulada y ambos están parcialmente desarrollados, la altura promedio es de 800 metros sobre el nivel del mar. Las tierras más altas incluyen parte de la cordillera de Guanacaste y sus prolongaciones hacia la región, son áreas quebradas casi no explotadas y cubiertas con bosques. ${ }^{9}$

Dados los distintos paisajes en el cantón, el clima es variable con temperaturas desde $22^{\circ} \mathrm{C}$ hasta arriba de $\operatorname{los} 30^{\circ} \mathrm{C}$, la humedad relativa ronda entre los 75 y $90 \%$ y las altitudes varían desde los 30 hasta 2.000 metros sobre el nivel del mar. También, las precipitaciones son abundantes desde los 1.600 hasta $3.600 \mathrm{~mm}$ por año, ocasionando desbordamientos de ríos en los meses más lluviosos desde junio hasta diciembre ${ }^{10}$. También existen diferentes zonas de vida en el cantón: bosque húmedo tropical al norte y al este, la de transición a prehúmedo $-<150$ metros-, bosque muy húmedo premontano y bosque muy húmedo tropical -de 150 a 500 metros- y bosque pluvial premontano $->500$ metros-. El sistema fluvial del cantón corresponde a la sub vertiente norte de la vertiente del Caribe y disfruta de las cuencas de los ríos Pizote, Guacalillo y Zapote. En sus límites administrativos se encuentran las cuencas de río Frío y del río Las Haciendas. ${ }^{11}$

A pesar de la inversión estatal y la ayuda internacional para levantar el rezago social y económico de este cantón, todavía sus índices se encuentran

8 Más adelante, en 1980, se creó el nuevo distrito de Yolillal.

9 Información tomada del producto de investigación de esta autora titulado, "Paisajes en la historia de Upala, 1950-1970", de la Escuela de Historia de la UNA. También presentada como ponencia en el simposio Historia y sustentabilidad. Lecturas desde la historia agraria y ambiental (Heredia, Costa Rica, Universidad Nacional, agosto de 2013).

10 Eduardo Chinchilla Valenciano, Atlas cantonal de Costa Rica (San José, Costa Rica: Instituto de Fomento y Asesoría Municipal-IFAM, 1987), 158.

11 Mario Samper Kutschbach, Transformaciones agrarias, experimentación e intercambio de conocimiento entre agricultores: análisis comparado de experiencias en Acosta-Puriscal y Upala, Costa Rica (Tesis de Doctorado en Sistemas de Producción para Agricultura Tropical Sostenible, Universidad de Costa Rica, 2007), 54 . 
entre los más bajos en cuanto a desarrollo social, humano y de infraestructura. El índice de desarrollo humano era el número 76 de los 81 cantones del país en el año 2000 y adelantó al puesto 73 en el $2005 .^{12}$

Ha sido un territorio de reciente colonización agropecuaria, primero en forma individual y familiar como lo expondremos con los análisis de las autobiografías campesinas, luego con el desarrollo colonizador establecido por el Estado costarricense y siempre con inmigración no organizada de nicaragüenses en búsqueda de mejores servicios y de trabajo. En 1973, el 16\% de la población que habitaba Upala había nacido en Nicaragua, el 67,1\%, en otro cantón nacional y solo el $16,8 \%$ era nativa del mismo cantón. ${ }^{13}$ En el siglo XXI:

\begin{abstract}
"Upala maneja alrededor del $10 \%$ de población transfronteriza, entonces alrededor de 5.000 personas que habitan la franja de $2 \mathrm{~km}$ en la frontera con Nicaragua ejercen presión sobre, precisamente esos servicios [educación, vivienda y salud], lo que ocasiona una presión sobre la eficiencia en la prestación de los mismos, ya de por sí, deficitarios en el cantón". ${ }^{14}$
\end{abstract}

En estas comunidades fronterizas, las familias no pueden tener título de propiedad por ser tierra del Estado costarricense, por lo cual se ven limitadas a obtener préstamos para las cosechas o para construir o remodelar sus casas. Por otra parte, su condición de frontera ha constituido una población flotante que reaparece en tiempos de cosechas para trabajar de jornalero o jornalera. $\mathrm{Y}$ en los últimos tiempos, los niños y las niñas nicaragüenses pasan diariamente la frontera para recibir lecciones en el territorio costarricense, las madres nicaragüenses también llegan a hospitales del país para servicios de salud, en especial para la atención de los partos. Por otro lado, algunos upaleños ${ }^{15}$ tienen fincas en territorio nicaragüense y se trasladan también a diario a cuidar sus cultivos o ganado.

Los habitantes de esas tierras antes del siglo XX eran en su mayoría aborígenes pertenecientes a la etnia de los guatusos y los malekus, solo tenían asentamientos temporales porque su economía dependía de la pesca, la caza y la recolección de yuca y pejibaye. Con el tiempo, hubo varias expediciones de sacerdotes y funcionarios del ejército costarricense a ese territorio para evangelizar a sus habitantes y velar por la soberanía de la zona fronteriza norte. Sin

12 PNUD. Atlas del desarrollo cantonal de Costa Rica. UCR-PNUD, San José, 2007. Disponible en URL: http://www.cr.undp.org/content/dam/costa_rica/docs/undp_cr_atlas_2007.pdf.

13 Oficial. Dirección General de Estadísticas y Censos -en ade-ante, DGEC-, Censos nacionales de 1973. Población (San José, Costa Rica: Ministerio de Economía, 1975).

14 Óscar Delgado y Gerardo Córdoba, Informe Comunidades Fronterizas Upala (San José, Costa Rica: Ministerio de Vivienda y Asentamientos Humanos, 2012), 3, disponible en URL: https://kipdf.com/ informe-comunidades-fronterizas_5ac899df1723dd2391d242d0.html.

15 Gentilicio de habitantes de Upala. 
embargo, arribaron también los vecinos nicaragüenses que extraían el hule en suelo costarricense atacando a los indígenas, los apresaban y llevaban a territorio nicaragüense donde regularmente eran esclavizados, ${ }^{16}$ quienes resolvieron dispersarse a lo ancho del territorio fronterizo norte.

En 1896, el obispo Thiel incentivó a los pobladores de Palmares, San Ramón y Naranjo a trasladarse a esas tierras lejanas, prometiendo que luego les mandarían un sacerdote. ${ }^{17}$ No tuvo mucho éxito su petición y hasta el año 1920 fue construida la primera ermita en territorios de los guatusos. Pero ya poblaban esas tierras nicaragüenses y algunos costarricenses que venían de las tierras altas de Guanacaste. El Estado y la Iglesia costarricenses procuraron consolidar la identidad nacional y católica en esa zona de frontera. ${ }^{18}$ Sin embargo, la articulación de este espacio a la patria costarricense fue lenta y hasta que se construyeron las carretas que lo enlazó con Guanacaste y de allí al Valle Central.

A continuación, se desarrollará el proceso histórico de la colonización de Upala antes de 1970 mediante el análisis de las autobiografías ampesinas con el fin de reconstruir el paisaje agrario, la migración y el asentamiento poblacional en ese territorio fronterizo norte. El punto de partida es la integración del agua y de la población colonizadora de Upala, donde se explicará la importancia del recurso hídrico en la vida cotidiana de aquella. En segundo lugar, se analizará cómo fue vista la colonización agrícola por aquellos habitantes y cuál fue la imagen que tuvieron de este paisaje. Se presentarán las rutas de los migrantes desde Nicaragua y otros sitios de Costa Rica para finalizar con el tema polémico de identidad territorial en una zona fronteriza.

\section{La integración de la tierra y la población alrededor del recurso agua}

El agua ha tenido una profunda representación simbólica para los habitantes y migrantes desde o hacia Nicaragua; los ríos, además de entregar el alimento por medio de la pesca, también ofrecían su líquido para las necesidades del hogar y de la finca; de la misma manera, era el único medio de transporte hacia el lago de Nicaragua y en especial hacia San Carlos de Nicaragua, puerto

16 Véase Marc Edelman, "Un genocidio en Centroamérica: hule, esclavos, nacionalismo y la destrucción de los indígenas guatusos-malecus", Mesoamérica, 36 (diciembre, 1998): 539-591, URL: http://www. mesoamericarevista.org/publicacion36.htm; disponible en URL: https://dialnet.unirioja.es/descarga/ articulo/2446202.pdf.

17 Elías Zeledón Cartín (comp.), Crónica de los viajes a Guatuso y Talamanca del Obispo Bernardo Augusto Thiel (San José, Costa Rica: EUCR, 2003).

18 José Aurelio Sandí Morales, "La participación de la Iglesia Católica en el control del espacio en medio de la creación de un país llamado Costa Rica (1850-1910)", Revista de Historia (Costa Rica) 63-64 (enerodiciembre, 2011): 53-99, URL: http://www.revistas.una.ac.cr/index.php/historia/article/view/4583. 
que se había constituido en el principal centro comercial, social y religioso de los habitantes de esta zona marginal.

\begin{abstract}
“El sistema del recurso 'agua' de hecho, ha sido considerado un elemento fundamental de la conexión ecológica y un importante factor en la formación histórica del territorio. Puesto que ella es el elemento que conecta los sistemas de flora y fauna a las estructuras de los asentamientos históricos, a las prácticas del uso del terreno, a las infraestructuras de la movilidad y a las relaciones territoriales, ha sido utilizada en la descripción normativa 'integración de los recursos' como matriz a través de la cual hallar las normas". ${ }^{19}$
\end{abstract}

Agua, tierra y población están imbuidas en el mundo de Upala. El territorio se componía de montañas y llanuras regadas por varios ríos y humedales, además de la cercanía y afluencia de aquellos al lago de Nicaragua. ${ }^{20} \mathrm{En}$ su conjunto, este forma parte de la cuenca del río San Juan que supera los límites políticos y administrativos de Nicaragua y Costa Rica, presentando una gran diversidad en el paisaje y en el medio ambiente. En el caso de Upala, en las tierras llanas se encuentran suelos aluviales debido al ancho de los cauces de los ríos y a su poco torrente, además de ser navegables en ciertos tramos. Se puede observar en el siguiente mapa:

19 Clara Copeta y Rubén Lois (coords.), Geografia, paisaje e identidad (Madrid, España: Biblioteca Nueva, 2009), 211.

20 Para mayor información se recomienda del Instituto Interamericano de Cooperación para la Agricultura(IICA), Programa de Desarrollo Rural (PDR) y Universidad de Costa Rica (UCR), Los Chiles, Upala, Guatuso y La Cruz: dinámicas territoriales en la zona norte de Costa Rica (San José, Costa Rica: IICA, 2007), disponible en URL: https://kipdf.com/los-chiles-upala-guatuso-y-la-cruz_5aaeac061723dd2a463a188d.html. 


\section{Mapa 2}

\section{Cantón de Upala: modelo digital del terreno y red hídrica (2013)}

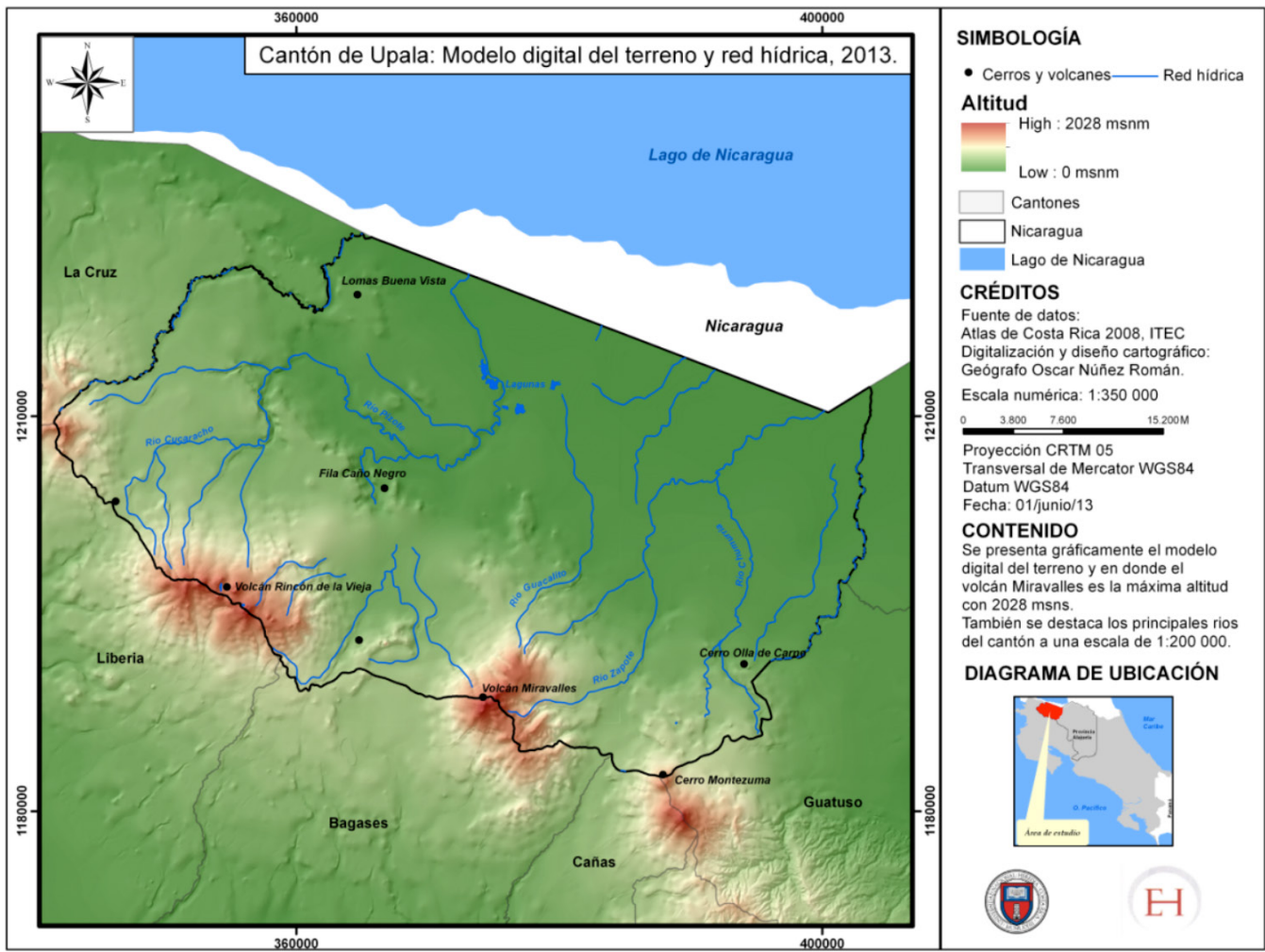

Fuente: Torres Hernández y Peters Solórzano (coords.), “Colonización y producción agropecuaria...".

También conforme el territorio se acerca al lago de Nicaragua se evidencian extensos humedales. Las dos lagunas más importantes son Las Camelias y El Pinol, que se les ha denominado también como ciénagas. Los mantos acuíferos y "las tomas" o captaciones de agua fueron abundantes en el cantón; sin embargo, en las últimas décadas han crecido actividades contaminantes que han fluido desde las partes altas a las más bajas y se han dispersado por medio de las vías fluviales.

En Upala, el río representaba elementos de atracción y de amenaza en ciertos meses del año. En primer lugar, el agua representaba la riqueza ecológica y paisajista, también para la agricultura, la ganadería, el transporte, la pesca, el turismo y la energía. Esta última representa hoy una amenaza por el desvío de las 
aguas de los principales ríos, que ofrecen a la población un sinnúmero de actividades que se eliminarán con varias represas en construcción. ${ }^{21}$

Algunas áreas se encuentran amenazadas por cambios en el uso del suelo, la deforestación, los incendios forestales y el dragado de humedales. También la pesca, la cacería y el uso de agroquímicos han minado la riqueza ecológica de Upala. A pesar de la creación de áreas protegidas, como algunos parques en la cordillera de Guanacaste, los humedales continúan siendo minados y toda la frontera con Nicaragua corre peligro eminente por la avanzada del cultivo de la piña que ha deteriorado el medio ambiente. ${ }^{22}$

En este siglo, se tienen planeados varios proyectos hidroeléctricos en Upala que responden al alza de la demanda de la electricidad y ha habido discusiones sobre las consecuencias nefastas para la biodiversidad y la economía del cantón, pues solo algunos empleos temporales se utilizarán durante la construcción. El nivel del agua de los ríos ha sido mermado y cuando se suelta la presa existe el peligro de una cabeza de agua, peligrosa para la población que vive a lo largo de los ríos. Por lo cual hay un cambio en la utilidad y la naturaleza de los recursos hídricos y de su simbolismo para la comunidad. ${ }^{23}$

Por otro lado, la abundante lluvia e inundaciones ponían en peligro la vida y las cosechas de los pobladores desde tiempos pasados. La precipitación en Upala aumenta hasta 578,9 mm mensualmente en algunas zonas del cantón durante la época de lluvia. ${ }^{24}$ En muchos casos, los caminos y los puentes entre poblaciones quedan inútiles y el transporte y la comunicación se detienen por varios días y en el peor de los casos, por semanas. Sin embargo, "al revés de las zonas secas del país, como Guanacaste, que por la sequía se han perdido este año miles de hectáreas de siembra, aquí or gracias de dios, nos sobra el agua". ${ }^{25}$

Los cultivos se encontraban amenazados por la ferocidad de las lluvias y el desborde de ríos, hoy día: "la cantidad de humedad que se pierde por escorrentía acumulada es bastante importante y podría ser la causa de deterioro en las zonas agrícolas, en la infraestructura vial, y principalmente del sistema de alcantarillado sanitario del cantón, especialmente de los centros de población debido a las constantes inundaciones, erosión hídrica, derrumbes y, en el caso de

21 Oficial. Comisión Nacional de Emergencias (CNE), Atlas de amenazas naturales (2008), URL: http:// www.cne.go.cr/Atlas\%20de\%20Amenazas/upala.htm.

22 Margarita Torres Hernández y Gertrud Peters Solórzano, "Informe de gira a Upala. Proyecto Colonización y producción agropecuaria en la zona fronteriza norte de Costa Rica: 1950-2010. I fase. Estudio de caso: Upala" (Escuela de Historia, UNA: 2013-2014).

23 Javier Córdoba, "Upala evaluará si declara moratoria a proyectos hidroeléctricos", Semanario Universidad, 26 de marzo de 2014, URL: https://semanariouniversidad.com/pais/ upala-evaluar-si-declara-moratoria-a-proyectos-hidroelctricos/.

24 Roberto Villalobos, Estefanía Jiménez, Karina Hernández, Johan Córdoba y Paula Solano, Descripción del clima. Cantón de Upala (San José, Costa Rica: Ministerio de Ambiente y Energía-MINAE; Instituto Meteorológico Nacional-IMN, 2013), 5, disponible en URL: http://cglobal.imn.ac.cr/documentos/ publicaciones/DescripciondelClimaSERIE/DescripcionClimaCantonUpala/index.html.

25 A.F.R., $A C$. Tomo XVI: 93. 
la actividad agrícola, de la pérdida de la fertilidad del suelo debido a la erosión de los suelos". ${ }^{26}$

J.R.G. contaba que al irse a sembrar cerca del río San Juan: "Ahí pasamos dos años con el agua a las rodillas noche y día y tanta agua me cogió tos y yo creía que está dañada". ${ }^{27}$ Además, la salud de los pobladores estaba constreñida no solo por problemas de vías respiratorias, sino por el zancudero que afloraba y permitía la transmisión de enfermedades tropicales, como la fiebre amarilla y otras.

Pero también encontramos temporadas de poca lluvia y de una humedad relativa baja que han arruinado cosechas y el pasto para el ganado. Los meses de agosto a diciembre son las temporadas de mayor humedad relativa, que concuerda con la siembra de arroz y otros productos. Mientras que, en marzo, cuando se inicia la cosecha de frijoles, la humedad es más baja y así los campesinos pueden secar sus granos al sol.

Las poblaciones estaban asentadas siempre cerca de los humedales y de los ríos y, en algunos casos, varios de estos demarcaban los límites de la villa. En la época lluviosa, las casas y los caminos sufrían calamidades por el desbordamiento de los ríos sobre los pueblos y las fincas agrícolas y ganaderas. La vida cotidiana se llevaba a lo largo de los ríos y riachuelos, decía un campesino: nosotros "seguimos luchando la vida hicimos un rancho a la orilla del río para cuando los güilas se me ensuciaban corría para el río a lavarlos sin jabón lavaba con oreja de Guanacaste y pepinillo...". ${ }^{28}$

Además, los ríos y humedales traían no solo la comida al hogar, sino también, ya en la década de 1970, la diversión para ir a pescar y pasear con la familia y amigos, veamos este relato:

\footnotetext{
"Resolvimos hacer un viaje y así fletamos un bote por quinientos colones entre cuatro, pero luego se nos arrimaron tres jóvenes norteamericanos de los del cuerpo de paz, que querían conocer territorio nicaragüense. Salimos un sábado del lugarcito denominado San Isidro a las seis de la mañana. Al principio el viaje fue muy bonito, pues el río muy amplio y limpio, no tuvimos ningún tropiezo, pero a la hora de caminar sobre el río, llegamos a una parte llamada el Yolillal; pues ahí estaba poblado de solo esa palma que llaman yolilla, y donde el río se riega por todo el terreno quedando solo un pequeño canal; ahí se para el motor y se sigue con un solo botavara y empujado, por hay partes donde no cabe el bote entre palera y palmera y así duramos más de dos horas, hasta que salimos de nuevo a lo limpio donde el río se hace más grande porque es una entrada del lago; pero ahí si es un paisaje maravilloso, donde las aves marinas revoletean y pescados de todas clases se ven a la orilla del bote, sobresaliendo los sábalos por su gran tamaño más de un metro y los gaspares que abundan y se desarrollan bastante también. También aparecen tortugas y uno que otro lagarto asoleándose en las orillas". ${ }^{29}$
}

26 Villalobos, Jiménez, Hernández, Córdoba y Solano, 18.

27 J.R.G., A.C. Tomo XIII: 73-75.

28 M.V.M.B., A.C. Tomo XIII: 119-120.

29 A.F.R., A.C. Tomo XVI: 89. 
Si la finca era aledaña a un río, los pobladores construían en primer lugar un bote para trasladarse y transportar la cosecha o traer los implementos que no tenían:

\begin{abstract}
"Me salió un joven de Cuatro Bocas que por qué no nos ponemos a trabajar en una finca, que tengo la finca es vida propia... Nos pusimos a trabajar con poco recurso. Lo primero que hicimos fue un bote, en ese bote bajamos a Colón a traer cepa de guineo, que en Cuatro Bocas no se encontraba la cepa, trepamos cincuenta y las sembramos éramos felices con cincuentas cepas, empezamos a criar chanchos los engordábamos con maíz zapotémico, coyolito y semillas de maquengue. Con los chanchos compramos una vaca en cuatro colones". ${ }^{30}$
\end{abstract}

Algunos recursos hídricos han desparecido pero su nombre lleva la herencia de antiguos suampos que ya sea por el cambio climático o por la acción del hombre, se han secado. Por ejemplo, Las Camelias en el norte de Upala. El sistema de cuencas hidrográficas en Upala es un espacio físico que recorre distintos distritos y poblaciones, estas han dado un sentimiento de pertenencia de los habitantes de esos lugares por el uso estratégico que se le ha dado a este recurso. A lo largo de los principales ríos se han fundado caseríos, pueblos y villas. El uso que se le ha dado a este recurso ha sido múltiple, de acuerdo con los intereses de individuos, familias, pueblos e instituciones estatales y empresas privadas.

Los ríos y sus pequeños puertos eran un sitio de encuentro y enlace de los habitantes, comerciantes y productores agropecuarios costarricenses y nicaragüenses, cuyo nodo de estas redes sociales y económicas se asentaba en el puerto de San Carlos de Nicaragua. En especial, el río Zapote que rodeaba varios poblados y, al ser el de mayor nivel de agua, se utilizaba con frecuencia para transportar las cosechas y personas hacia el lago de Nicaragua.

Desde el inicio de la expansión de la frontera agrícola los pobladores se dedicaron al comercio, las redes trascendieron el espacio fronterizo estableciéndose con San Carlos de Nicaragua un enlace fuerte: "pusimos un negocio, constándonos mucho pues la mercadería la íbamos atraer asta Nicaragua. Porque no teníamos la comunicación con ninguna ciudad de costa rica caña no existía pues todo lo traíamos de Rivas Nicaragua con mucha dificultad el primer pueblo que salimos fue a Liberia en ese tiempo". ${ }^{31}$

Antes de que hubiera una carretera que comunicara a Upala con Cañas, los pobladores utilizaban el río Zapote como guía en el camino, caminaban por la orilla y, desde luego, encontraban algunos tropiezos como los barreales y los humedales. Recordemos que la principal villa era Upala y ese pueblo ha sido

30 B.B., A.C. Tomo XIII: 112.

31 B.B., A.C. Tomo XIII: 112. 
atravesado por el río Zapote. La villa se podía comunicar con Los Chiles y Guanacaste por tierra, era un camino trazado como un trillo; entonces, solo se podía pasar a caballo o a pie topándose con charrales y lomas pronunciadas y durante la estación seca.

En la segunda mitad del siglo XX, los pobladores de Upala tuvieron la necesidad de mejorar la comunicación terrestre con el resto del país, como lo menciona H.R.S.: "Viendo mi papá que esta era una Zona próspera y de gran esperanza Nacional pro la fertilidad de sus tierras, le dio la idea a Papá de mandarle una Carta al Ministro Don Carlos Manuel Rojas su buen y Viejo Amigo, haciéndole ver la necesidad de una Carretera para la Región de Upala". ${ }^{32}$ A pesar de que la misiva fue contestada con brevedad, la construcción de la carretera se atrasó varios años más. La falta de vías de transporte era una de las flaquezas que sufría ese territorio norte, que limitaba la oferta de mano de obra para la agricultura. ${ }^{33}$

A pesar de que el gobierno había mostrado interés, la comunidad se organizaba para construir parte de la infraestructura. Se formaron juntas progresistas para desarrollar sus comunidades, tales como caminos, puentes, la escuela y otros. La construcción de carreteras no solo incidió en un cambio del paisaje, sino también en el entretejimiento de las redes sociales, comerciales, cambiando la percepción los "upaleños" hacia las otras regiones del país y viceversa. El imaginario territorial del costarricense acerca del nuevo cantón de Upala y sus habitantes fue surgiendo de forma lenta, a través de las noticias en los periódicos y la radio nacional, estas informaban sobre sus acontecimientos semanalmente.

32 H.R.S., A.C. Tomo XIV: 28.

33 Diario de Costa Rica, "Los agricultores de Upala piden permiso para trasladar trabajadores de San Carlos", 27 de agosto de 1949, p. 3. 


\section{Mapa 3}

\section{Cantón de Upala: división por distritos (1987)}

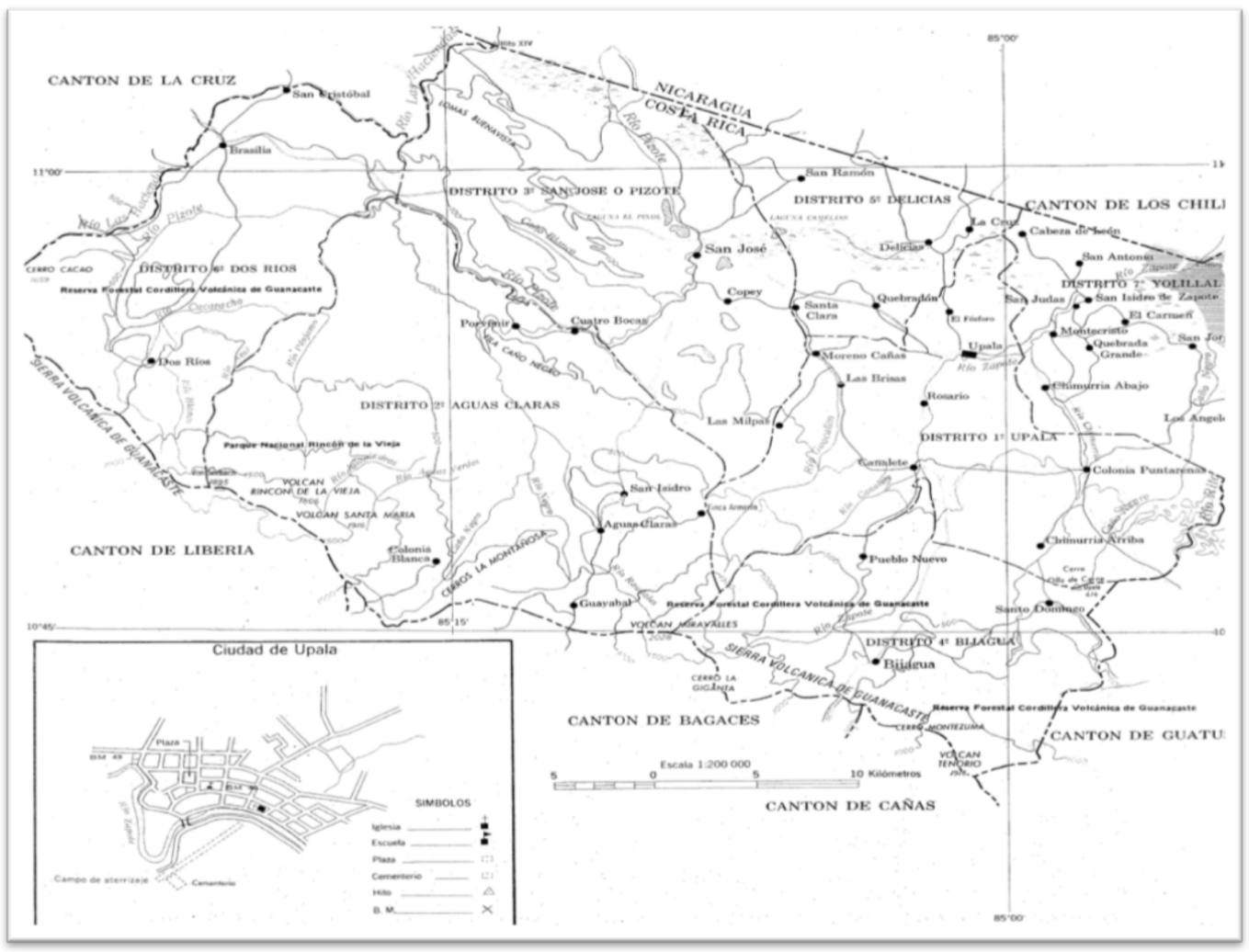

Fuente: Eduardo Chinchilla Valenciano, Atlas cantonal de Costa Rica (San José, Costa Rica: Instituto de Fomento y Asesoría Municipal-IFAM, 1987), 156.

La relación directa de la población y el recurso hídrico no solo estuvo caracterizada por la conveniencia social, personal y económica, también representaba una amenaza en tiempo de mucha lluvia. Pero nada ha sido tan catastrófico como el paso del huracán Otto en noviembre de 2016, cuando este entró a territorio costarricense y no bajó su intensidad, como se creía, tomando como ruta Los Chiles, Upala y Abangares. Ha sido el peor estrago en la zona, dejó 100 fallecidos, 40.000 afectados y miles de millones de colones en pérdidas materiales. El agua sepultó a pobladores, casas, cultivos, ganado y otros animales, comercios, las cañerías de agua potable, los postes de electricidad y edificios públicos. El meollo del problema ha sido la construcción en sitios con gran 
riesgo de inundaciones o avalanchas de los ríos, en especial el río Zapote. En un principio no se midieron los riesgos y los asentamientos fueron construidos de forma desordenada, las áreas de posibles inundaciones fueron ocupadas, así como los efectos de una deforestación en la cuenca alta y media del río Zapote. Sin embargo, el mayor error para enfrentar esta catástrofe fue la desinformación de la población ante estos riesgos. ${ }^{34}$

\section{Una colonización agrícola lenta y heterogénea en la historia de Upala}

Muchas de las familias que han residido en este cantón son descendientes de antiguos nicaragüenses y así lo han descrito esos campesinos en las autobiografías. Numerosos extranjeros se instalaron en el distrito Yolillal, antiguamente parte del territorio del distrito de Upala y colindando con Nicaragua. Yolillal era muy atractivo por ser zona de frontera, con pocos habitantes costarricenses y además tenía salida directa por el río Zapote a Nicaragua y a su lago. Por tierra era muy difícil llegar hasta ese lugar por los pantanos y ríos que se tenían que cruzar. Además, no contaba con caminos, sino que existían algunas trochas para abastecerse o comunicarse con el centro de Upala. El bosque fue cortado poco a poco para usar la madera en construir barcas y casas. También para preparar el terreno con el fin de sembrar maíz, frijol y cacao. En general, la carne la conseguían gracias a la cacería, a la pesca y a cerdos domesticados, de estos últimos obtenían la manteca para usarla en la cocina, que se conservaba por varios meses.

Los otros dos sitios donde arribaron nicaragüenses fueron Upala y Cuatro Bocas de San José. En Upala la actividad era más diversificada y las mujeres podían hornear, en artefactos hechos de barro, productos de maíz o de harina de trigo y venderlos en la villa. Cuatro Bocas era un sitio más lejano del centro de Upala y con poca atracción de mano de obra. También tenían ambos sitios salida fluvial a Nicaragua, Cuatro Bocas por el río El Niño y a Upala por el río Zapote. Por otro lado, el antiguo distrito de Upala, que incluía a Yolillal y San José, tenía un patrón de uso del suelo similar en 1973: casi un 40\% de bosques y montes, los pastos sumaban casi un $28 \%$, los charrales un $17 \%$ y apenas un $15 \%$ del territorio estaba dedicado a la agricultura. ${ }^{35}$

Los migrantes nacidos en Costa Rica venían de zonas tan distantes como la región Pacífico Sur, del Valle Central y del cantón de San Carlos -Villa Quesada-. Entraron al cantón por vía terrestre y en algunos casos por vía aérea. Las

34 Álvaro Murillo y Hulda Miranda, “PPor qué el huracán Otto azotó así a Upala?”, Semanario Universidad, 30 de noviembre de 2016, URL: https://semanariouniversidad.com/pais/huracan-otto-azoto-asi-upala/.

35 Oficial. DGEC, Censos Nacionales de 1973, 76-183. 
rutas eran por Cañas o por Bagaces, los dos cantones de Guanacaste, atravesando las honduras que se localizaban en los volcanes Rincón de la Vieja, Miravalles y Tenorio. Algunos se guiaron por el sitio llamado La Cabanga, en especial si habían cruzado Tilarán. Igual que los colonos extranjeros, la misión de estas familias era encontrar trabajo o un pedazo de tierra para labrarla, en la mayoría de los casos se tumbó el bosque para dar lugar a la agricultura y luego ganadería. Se cosechaban maíz, frijoles, arroz, plátanos y yuca. A veces tenían cerdos y pocas veces obtuvieron una vaca para el consumo de leche.

Upala centro era un sitio atractivo para los migrantes por la diversidad de sus actividades, no solo la agricultura, sino que había un poco de industria artesanal, comercio y algunos servicios del Estado, como escuela y policía. La mayoría de los costarricenses se localizaban en este distrito central. Canalete fue otro de los lugares escogido para llegar a vivir, estaba muy cerca de Bijagua y de allí se llegaba a Cañas. El suelo estaba consagrado preponderantemente a bosques, pastos, charrales y poca agricultura. Este poblado ha sido concebido como el sitio de encuentro entre las dos nacionalidades, los nicaragüenses que llegaron por vía fluvial de norte a sur y los costarricenses que cruzaron montañas para habitar estos bosques y luego llanuras. En menor número, los colonos nacionales se dirigieron a Yolillal o San Isidro de Upala y a Aguas Claras. Este último lugar tenía la particularidad de encontrarse cerca de Bagaces, desde donde partían por vía terrestre recorriendo a pie trochas angostas hasta llegar a Aguas Claras, donde no había caseríos en aquel entonces, sino familias dispersas por el territorio. Este distrito tenía más influencia de la cultura guanacasteca y muy buenas condiciones para el ganado vacuno y caballar, aunque los bosques eran parte muy importante de la ecúmene y, por último, se encontraba la agricultura y los terrenos de charrales.

Todavía en 1952 en Canalete de Upala se encontraban zonas vírgenes donde habitaban animales pertenecientes al bosque mencionados por varios agricultores. Al principio de la expansión, los zancudos o mosquitos parecían ser parte intrincada de dicho proceso, pero también "se encontraban animales salvajes, de distintas clases, tales como tigre, león, danto, cariblancos, saínos, tepezcuintes, cabra, venado, manigordo, congo, mono, pavón, paba y otras más". ${ }^{36}$

En las décadas de 1950 y 1960 todavía descubrirían zonas sin colonizar lo que representaba una fuente de acceso a la tierra, para aquellos que se encontraban desventajosamente en términos de posición de recursos. Por ejemplo, Upala era una zona repleta de montañas, de donde R.S. comentaba que desde 1952, "vista de nuestra obligación era cada día más grande y la situación económica se estrechaba cada véz más, decidimos por venir a Meternos a estas Montañas de Zapote de Upala donde hoy vivimos". ${ }^{37}$ Con la formación de tramos de

36 H.R.S., A.C. Tomo XIV: 38.

37 R.S., A.C. Tomo XVI: 26. 
comunicación entre Upala y Guanacaste, la zona representó una nueva oportunidad para migrantes guanacastecos. Desde el cantón de La Cruz arribaron agricultores que tenían ascendencia nicaragüense.

La conformación de Upala implicó para sus pobladores trabajo dentro de las montañas que seguidamente las transformaron en fincas, según los colonizadores esto fue una tarea difícil: "la vida a sido muy dura para nosotros los campesinos y casi todos los que abrieron estos bosques se han muerto somos los que hemos quedado". ${ }^{38}$ Se refería a las muertes por mordedura de serpientes, estos animales llegaron a trascender en el imaginario de los upaleños cuando botaron el bosque y el monte. A falta de médicos y farmacias, los colonizadores tenían remedios naturales para curar esas heridas.

Varias familias arribaron a Upala después de probar suerte en otros sitios, en Nicaragua, así como en Costa Rica. M.B.G.T., junto con sus familiares, hizo un largo recorrido desde la zona sur hasta Upala. La muchacha escribió:

\begin{abstract}
"Cuando llegamos a Aguas Claras un señor nos prestó un pedacito de terreno para construir un ranchito. Porque la finca era solo montaña y quedaba a una hora y media a caballo. En este ranchito vivimos un tiempo, de aquí viajaba mi gente a voltear montañas en Las Armenias...Cuando papá había recogido nos cincos decidió irse a traer el resto de la familia...Una vez estábamos todos y ya había los suficiente volteando se hizo el rancho. Este rancho fue construido con troncos de árboles y ramas, su techo estaba tejido con hojas de suita amarradas, con bejucos. Las paredes eran de chonta sí como las camas y el tabanco, los bancos eran trozos de tronco de árboles". ${ }^{39}$
\end{abstract}

\title{
Años después, esta familia compró otra finca en Los Cartagos: ${ }^{40}$
}

"[...] la cual quedaba como a tres horas a pie montaña adentro cuesta abajo...Supe también lo que fue acompañar a papá a tapar frijoles, sembrar maíz y tapizcarlo, cortar arroz aporriarlo, aporriar frijoles, sembrar piñas, yuca y todo lo que en cultivo se refiere. Los racimos de plátanos los jalábamos en una vara y los cargábamos así era la forma más cómoda. Las gallinas también las sacábamos a vender en varas colgando. En esta finca 'Los Cartagos' todo era montaña, el ranchito se encontraba rodeado de un frijolar y matas de maíz". ${ }^{41}$

Otro relato sobre la difícil entrada a las montañas de Upala nos lo relata B.U.:

38 B.U., A.C. Tomo XVI: 147.

39 M.B.G.T., A.C. Tomo XII: 36-52.

40 Población cercana a San José de Upala.

41 Esta narración debe haber sido en la década de 1960. Ella nació en 1950 y, a la edad de 15 años, la mandaron a trabajar de empleada doméstica a la capital, San José. Págs. 42-43. 
"Entré a este lugar de edad de 8 años, [1907] hicieron mis padres un ranchito, en una montaña porque en estos bosques no existía, casi nadie sufriendo de toda cosa picado de zancudo y toda clase de bicho me iba hacia adentro de la montaña, a hacer mis necesidades, y hasta un tigre me escapaba de comer, donde habían muchos yolillales en el río, y donde quiera, la vida ha sido muy dura para nosotros los campesinos y casi todos los que abrieron estos bosques... Yo me dedicaba a sembrar maíz, arroz, frijoles, guineo el terreno lo preparaba cortando con machete y hacha y luego pegaba fuego y con un palo con punta hacía huecos para sembrar". ${ }^{2}$

En ese entonces, el poblamiento era espontáneo y gradual y los hogares eran construidos con los materiales naturales que tenían a su alrededor. Mientras que, con la colonización masiva producida por el Estado costarricense, los poblados se fueron construyendo en forma nucleada con diversos materiales, atendiendo necesidades nacionales, así como de protección de la frontera norte.

\section{Fotografía 1 \\ Cantón de Upala. Rancho en construcción (1963)}

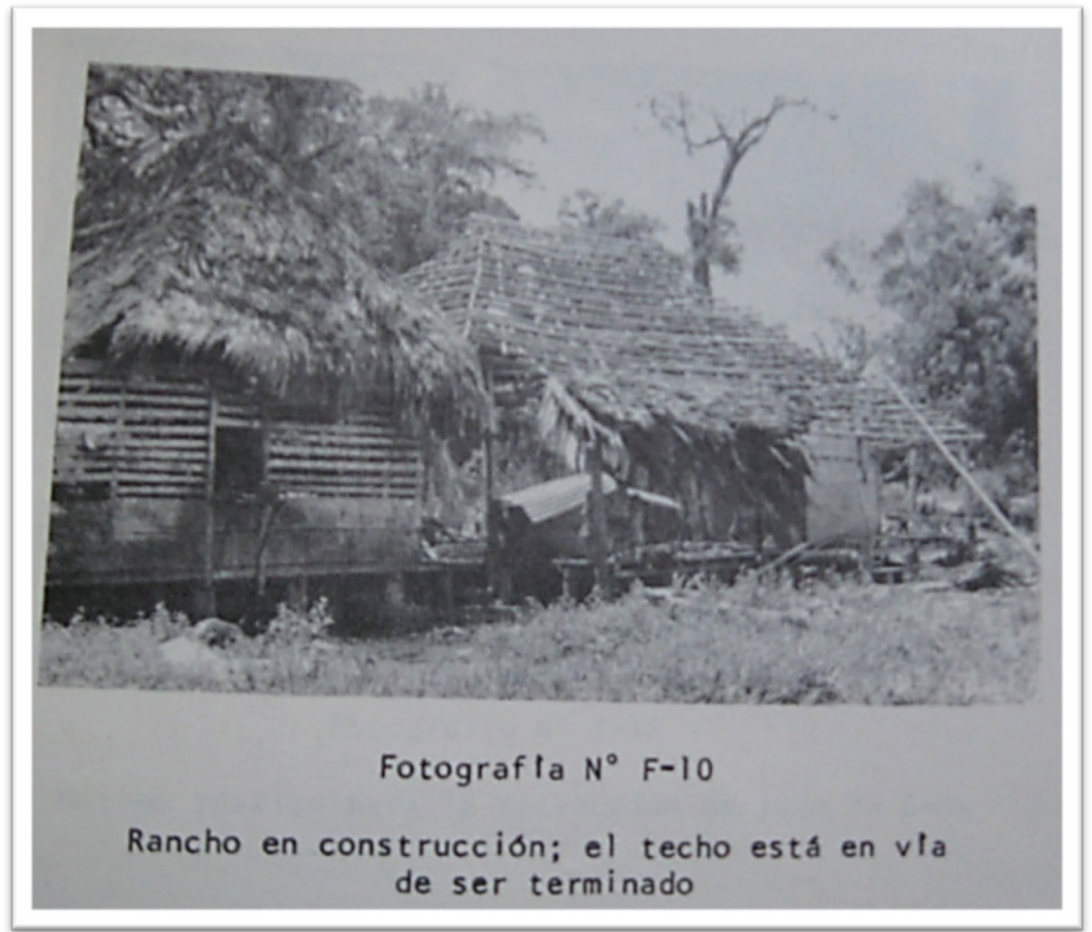

Fuente: (ITCO), Estudio de la región de Upala.

42 B.U., A.C. Tomo XVI: 147-148. 
Las necesidades alimenticias de los pobladores se desahogaban con los recursos naturales que tenían a mano. En la zona había muchos monos y estos se transformaron en un recurso alimenticio para los pobladores que se dedicaron a las primeras deforestaciones, al no haber comida a la mano, animales salvajes fueron cazados y su ingesta fue una forma de suplir las necesidades, como el saíno y algunas aves. El mono lo comían asado o sancochado y le ponían sal, sí tenían este condimento. ${ }^{43}$ Las vírgenes montañas representaron una fuente de alimentación por varias décadas como lo deja plasmado Adolfo R.S. quien tenía "un perro bueno para la Cacería". ${ }^{4}$

La cría de cerdos fue una práctica desde las primeras décadas del siglo $\mathrm{XX}$, sin embargo, como el lugar se encontraba rodeado por bosque había tigres los cuales se comían los cerdos, entonces las personas buscaban mecanismos de vigilancia, según B.B. "para evitar el daño del tigre dispusimos que los chanchos durmieran debajo de las camas donde nosotras dormías". ${ }^{45}$

No todos los "colonizadores" de estos nuevos terrenos tuvieron acceso a la tierra de forma privada, muchos tuvieron que laborar en fincas ajenas o crearon pequeños negocios vendiendo sus comidas, en especial las mujeres:

\footnotetext{
"el señor [compañero de la muchacha] me hizo un horno de barro allí vivía trabajando y me levantaba a la una de la mañana a moler 3 cuartillos de maíz para hacer cosas de horno para ir a Upala [se refiere al pueblo] a vender después de hornear me iba hasta la hacienda de Sanpiere [otros pobladores nombran esta hacienda] a vender después compraba harina para hacer pan con el interés que me quedaba el saco para vestir a mis hijos...". ${ }^{46}$
}

Otros, sin la suerte por adquirir tierra, llegaron a Upala a trabajar como peones o jornaleros. Una de las fincas que daba trabajo era la de San Pierre, situada en el actual distrito central de Upala. Cuando se recopilaron las autobiografías campesinas en 1977, dos de las personas que participaron dejaron plasmadas demandas en relación con sus necesidades como fueron las de vivienda, tierra o trabajo, en el caso de R.A.R.G. había vivido varios años en la zona, siempre fue jornalero y en ese momento se encontraba enfermo y sin casa, mientras que él veía injusto que la madera que se extraía del lugar no se aprovechara bien y él pedía a los dueños de la misma que deberían regalársela para hacer su casa. ${ }^{47}$

En estas demandas se evidencia que los dueños de las fincas no se apegan a las normas laborales y no cubren las necesidades médicas de sus empleados, y cuando estos se encontraban en una condición desfavorable de salud,

43 Ibid, 147.

44 A.R.S., A.C. Tomo XVI: 23-30.

45 B.B., A.C. Tomo XVI: 107.

46 M.V.M.B., A.C. Tomo XII: 111.

47 R.A.R.G., A.C. Tomo XV: 251-252. 
simplemente no eran contratados. La situación se empeoraba cuando había alta oferta de jornaleros, esto era traducido en pobreza que asechaba a algunos pobladores de la zona.

Por otra parte, uno de los productores que redactó una autobiografía, A.F.R., nos cuenta que también buscaban tierra del otro lado de la frontera costarricense. Había unos terrenos baldíos a la orilla del lago de Nicaragua, en la desembocadura del río Zapote:

\begin{abstract}
"De regreso, a la orilla del lago en la desembocadura del río Zapote, nos dedicamos unos a pescar y otros a preparar la comida. Yo me fui con uno de los compañeros a la desembocadura del río Negro, [río fronterizo con Los Chiles], a ver los terrenos que pensamos ir a cultivar. Anclamos el bote y nos bajamos; pero ahí creí yo que iba a dejar el cacaste, porque el lodo era tanto que y tan hondo, que se quedaba uno segado. Ayudándonos con una vara pudimos salir; pero yo en un momento dado me quedé pegado y si no hubiera sido el compañero ahí hubiera perecido, porque solo no podía salir". ${ }^{48}$
\end{abstract}

Algunos pobladores amasaron fortuna en las tierras de Upala y a través de estas se pudo diseñar un nuevo pueblo. Por ejemplo, B.B. y su marido tuvieron una finquita en Cuatro Bocas y fueron extendiendo sus posesiones hasta el punto de ceder tierras para la construcción de ese pueblo. B.B. estuvo colaborando en la Junta de Educación, en la Junta Edificadora de la ermita y en otras labores más. Fue presidenta de la Junta Progresista, con la ayuda del pueblo construyeron un puente y, además, dispuso hacer un cuadrante en la propiedad de ella, y construyó ocho calles: "dí terreno para la plaza, la ermita, el puesto de salud, la escuela, el salón comunal por todos estos terrenos cubica 28.592 varas cuadradas espero que ustedes tomen aprecio de esta labor. Más dos tercios del terreno del campo de aterrizaje y muchas labores más...". ${ }^{49}$ Es interesante porque la mujer fue la que tomó la iniciativa de donar sus tierras y participar en las juntas progresistas, ya su marido había fallecido.

La niñez era triste en aquellos años por la pobreza y las condiciones ambientales, además carecían de cualquier servicio como agua, luz, educación y de médicos. Nos cuenta doña M.V.M.B., que en 1914:

\begin{abstract}
"Entré de la edad de 8 años casi me muero de aflicción en ver que no habían casa ni gente en el lugar los que habían bosque lluvia y plagas de zancudos y barros, no teníamos toldo andaba vestida con sacos de harina, nos alimentábamos con frijoles sancochados y no teníamos platos ni cucharas...cuando estábamos enfermos nos curábamos yerbas de monte porque no habían doctores, ni tráfico para el centro ni comandancia, 3 guardas eran los que habían escuela no habían por eso no aprendimos a leer sé un poco gracias a mi mamá que ella sabía y sobre la pobreza
\end{abstract}

48 A.F.R., A.C. Tomo XVI: 90.

49 B.B., A.C. Tomo XIII: 116-117. 
de nosotros no pude aprender más, cuando tenía 11 años me ponían a moler en piedra...me molía un medio de maíz para ganarme 5 céntimos así fui creciendo y luchando la vida en la mañana mi papá me llevaba a trabajar al machete y enseguida cuando llegaban las cosechas nos llevaban a cortar arroz a coger maíz y frijoles llegábamos a la casa a hacer comida que era arroz y frijoles y sancochado comíamos la carne porque mi papá iba de cacería era carne de monte...". ${ }^{50}$

Muchas de las niñas eran obligadas a trabajar como cocineras en las fincas de su familia, y a veces debían cocinar y lavar para los peones o jornaleros que estaban en la propiedad. La pobreza era una realidad en la vida de los niños, haber pasado hambre y trabajo era la norma de la vida en esta zona de frontera, además de la falta de servicios: "En ese tiempo [1956] no teníamos servicios médicos, los niños no tomaban leche de vaca porque del todo no se hallaba. La mortalidad de los niños al como alo macuimo, debido a la desnutrición, la epidemia del zancudo y parásitos intestinales". ${ }^{51}$

$\mathrm{Al}$ no haber electricidad prendían el fuego con hule y se alumbraban con mechones de cera. Cuenta B.B.: La primera escuela; "como lla habían barías casas, díspuse traer un maestro dándoles todas las comunidades, daba clase en el corredor de las casa". ${ }^{52}$ A pesar de que podría haber una humilde infraestructura de la iglesia, esta no tenía una presencia de sacerdotes, pues en la década de 1930 aproximadamente, P.P.C. se vio en la obligación de trasladarse hasta San Carlos de Nicaragua para casarse por la Iglesia católica.

\section{Redes familiares-sociales en la migración hacia este nuevo territorio}

Tal como se escribió en el anterior apartado, pocos productores agrícolas habían nacido en Upala, la mayoría venían de Nicaragua o del resto de Costa Rica. Estas autobiografías revelan características distintas a la norma de la colonización agrícola desde el Valle Central hacia otras zonas periféricas. La migración no partió desde las regiones cafetaleras de aquel valle, sino que fue un proceso de poblamiento disperso hasta los años 1960 y luego organizado por el Estado costarricense. Además, se debe considerar la importancia de la migración de nicaragüenses en la región norte, quienes podían fácilmente llegar a Upala por medio de las vías fluviales.

Las redes eran primordialmente de carácter familiar, en algunos casos de amigos. Otros migrantes se aventuraron a abrir la frontera agrícola en la zona sin contar con vínculos en el sitio. En la década de 1960, Upala todavía tenía bosque virgen, entonces ya algunos costarricenses habían migrado hacia el sitio.

50 M.V.M.B., A.C. Tomo XIII: 1.

51 H.R.S., A.C. Tomo XVI: 38.

52 B.B., A.C. Tomo XIII: 113. 
La autobiografía de M.B.G.T., ya mencionada, trata sobre esa travesía en dicho proceso, pues su familia se fraccionó en el viaje ya que unos se fueron primero y otros después, ella se fue de primero con algunos de sus hermanos y su papá. Antes de llegar a Aguas Claras, ella cuenta que había nacido en la Finca Seis de la zona Pacífico Sur en 1950, luego su padre dejó las labores agrícolas y viajaron hacia Ciudad Cortés, donde su papá tuvo varios trabajos como vendedor de lotería, vendedor de huevos y después pasaron a vivir a una finca y ella les cocinaba a los peones del lugar. Migró la familia a Las Juntas de Abangares y su papá consiguió el puesto de policía. De allí partieron por más de tres días hacia Aguas Claras pasando por Bagaces. Se establecieron en Las Armenias y luego en Los Cartagos de Upala.

En otros casos, los nuevos habitantes de Upala habían migrado desde Nicaragua. La autobiografía de B.B. es muy interesante por el traslado constante apoyado por las redes familiares. Ella nació en Chontales, Nicaragua, pero después se trasladó a Granada con su madre, luego a Masaya y a los quince años se casó. Su matrimonio fue corto porque su marido murió. Se sentía sola y un tío que se encontraba establecido en Upala le ofreció que fuera al lugar como comerciante, por lo cual se aventuró. La ruta fue la siguiente: "nos embarcamos en la Rafaela era una lancha que hacía gira por Colón llegamos a Colón ahí mi tío tenía un bote de palanca y canalete así trepamos en el río hasta que llegamos a San José de Upala". ${ }^{53}$ Ella se quedó viviendo en Cuatro Bocas por 45 años, cuando redactó su autobiografía.

Otra vía para migrar hacia Costa Rica era llegar a la Punta Alemán, en el lago de Nicaragua y que conecta con el río San Juan, y luego tomar el camino hacia Las Delicias de Upala. En medio de montaña y tacotales había que seguir la trocha hasta los primeros poblados al norte del cantón.

En aquel entonces, casi toda la actividad comercial se realizaba directamente con Nicaragua. La funcionalidad del comercio radicaba en comprar productos en Nicaragua y venderlos en la zona norte de Costa Rica, pues esta no tenía comunicación con otras zonas del país. Upala en un principio solo tenía comunicación con Nicaragua, pues en "Upala solo circulan los córdobas los colones solo le llagaba a los guardas o sea a los empleados del gobierno que aunque en su gran mayoría eran nicas pero el pago les venía de Costa Rica". ${ }^{54}$ Por la falta de vías de comunicación los costarricenses de otras zonas no iban a trabajar al lugar y la actividad económica era reducida.

La estrechez económica y la falta de posesión de un pedazo de tierra obligaban a los futuros pobladores de Upala a migrar hacia otros sitios. Veamos, 
J.G.R. nació en Granada, Nicaragua, el 18 de setiembre de 1925, sus padres eran muy pobres por lo cual no tuvo educación escolar, luego a los doce años una hermana la engañó de que la traía a Costa Rica y la dejó en San Carlos de Nicaragua, donde trabajó en una casa y en el año 1944 se fue a Los Chiles, sitio contiguo a Upala, y tomó un avión hacia San José. Luego tuvo un negocio en Alajuela, se mudó a Golfito y regresó a la zona norte, a Villa Quesada, donde compró una casita y siguió trasladándose hasta que llegó a Upala en 1952. Allí tuvo siete hijos y trabajaba en el monte sembrando frijoles, maíz y arroz. Además, cuando no había cosecha sacaban guaro de contrabando. Luego la situación económica se puso difícil y se mudaron al río San Juan a sembrar granos básicos. Después a la isla de Chira en el golfo de Nicoya y a Golfito, donde vivió con su hijo que trabajaba en la Compañía Bananera. Al paso de cinco años, se devolvió a Upala con un nietecito. ${ }^{55}$

Muchas veces los inmigrantes nicaragüenses estaban colindando con las dos fronteras, en suelo costarricense o nicaragüense. Algunos de ellos habían dado vueltas por distintos poblados buscando trabajo o tierra. En el caso de P.P.C. había viajado a "Casa Quemada" en el noreste de Upala y luego se fue a casar a San Carlos de Nicaragua, pues en ese entonces no había cura en Upala. Pero en su niñez anduvo con la maleta al hombro por más de cinco años, trabajando de jornalero con solo doce años en su tierra natal. En 1926:

"cuando vinieron los aviones junio en 1926 cuando estaban los americanos estaban en Nicaragua cuando a Santa Clara entré de 17 años mi patrón era Alfredo G, no se conocía el colón sino el córdoba allí trabajé 3 semanas... allí ganaba 50 centavos, de allí me fui para San Carlos de Nicaragua. De allí me vine para San Isidro de Upala de Costa Rica entonces se llamaba Yolillal primero donde trabajé en un punto que le llamaban 'Guanegra'...". ${ }^{56}$

Nombraba algunos lugares del cantón: San Jorge, Caño Rito, Montecristo, 4 casas de palma que ahora es el centro de Upala, San Antonio, Casa Quemada, Quebrada Grande, el Jobo Mongrito, en todos estos lugares trabajaban los nicaragüenses. Se hablaba de que en las colonias ofrecidas por el gobierno de Costa Rica casi siempre vivían costarricenses, fuera de éstas todos están revueltos, ticos y nicaragüenses. ${ }^{57}$

55 J.G.R., A.C. Tomo XIII: 2-3.

56 P.P.C., A.C. Tomo XVI: 2.

57 Fincas de Valentín San Pierre, Upala centro. 


\section{La identidad territorial de la población fronteriza norte}

En este apartado se analizará la relación entre los conceptos de identidad, paisaje y frontera nacional. La identidad es una descripción que se construye, o sea, es una invención de los pobladores de un territorio que toman la decisión de caracterizarse de determinada manera, muchas veces creando también la diferencia con otras poblaciones y territorios. En palabras de Rubén Lois y Miguel Pazos:

\footnotetext{
"La noción de identidad hace referencia al sentimiento de adhesión que un individuo o colectivo de individuos experimentan hacia una serie de atributos geográficos, históricos, psicológicos, ambientales, lingüísticos, religiosos y, en general, culturales, que se viven como propios, ya sea individual o colectivamente. En la misma noción de identidad subyace, por lo tanto, el reconocerse en el espejo de una serie de pautas culturales que ha ido desarrollando la sociedad a lo largo de la historia". ${ }^{8}$
}

El paisaje tiene un trasfondo cultural, social y natural, mantiene su significado en un tiempo determinado y en un territorio establecido donde sus fronteras pueden ser movibles y en nuestro caso no atañen a la nación, en forma directa.

Como el objeto de nuestro estudio está en una zona fronteriza, este acarrea matices distintos y compartidos con los pobladores del otro lado de la línea fronteriza. Lógicamente que los estados nacionales influyen también en la formación de la construcción de esa consonancia; sin embargo, en territorios fronterizos ha sido difícil irradiar esas semejanzas entre territorios tan alejados del centro político de una nación. En Costa Rica, la construcción de la identidad nacional fue construida desde el Valle Central, totalmente incomunicado con Upala hasta los años setenta del siglo XX. El Estado y la Iglesia católica crearon y legitimaron conjuntamente las características de ese "costarricense" que fue extendiéndose conforme se ampliaba la frontera agrícola. En Nicaragua, la identidad nacional incluía solo a las poblaciones del Pacífico, donde se concentraban las principales ciudades, las instituciones públicas y la economía nacional.

¿Qué significado ha tenido la línea fronteriza para los pobladores de la frontera norte? En realidad, solamente en ciertos lugares existen puestos de migración que solicitan permisos e inspección al sobrepasar esa línea. Pero, en otros tiempos atrás, la movilización de los habitantes era libre y todavía existen migraciones diarias de niños que vienen a Upala a estudiar o de madres que necesitan de servicios de salud en Costa Rica. Además, trabajadores y propietarios de fincas agrícolas y pecuarias deben cruzar esa línea todos los días para seguir con sus actividades cotidianas. Entonces, el paisaje representa una continuidad en esa zona y la organización del espacio agrario se revela de

58 Lois y Pazos, 233. 
forma similar, con algunas diferencias en cuanto a los servicios públicos que mantienen las dos naciones colindantes:

\begin{abstract}
"Un Domingo hicimos un viaje, para ir a un lugar llamado Punta Alemán. Para ir a este lugar hay que pasar por Delicias, que de Delicias no tiene nada. Luego seguimos por unos takotales, por unos caminos intransitables, hasta que llegamos a la finca el coral y de ahí a la orilla del lago por una trocha, pero como mi carro es doble tracción tatallando pero llegamos. Una vez en la playa, que por cierto no son playas, porque hay mucho lodo, y en partes se quedaba uno pegado y para poderse bañar hay que internarse docientos o mas metros dentro del lago para poder estar tranquilo. Estuvimos recojiendo almejas y pescando y paseando a lo largo de la orilla". ${ }^{59}$
\end{abstract}

La toponimia de algunos sitios de Upala tiene relación directa con la interpretación simbólica que los upaleños les han otorgado a la cultura y a la naturaleza. Pocos nombres tienen antecedentes indígenas, por ejemplo, Upala que significaba casa cerca del agua, era voz maleku. ${ }^{60}$ Como esta zona fue colonizada muy tarde, algunas toponimias indígenas no fueron rescatadas y acabaron en desuso.

Otros nombres hacen referencia a fenómenos naturales, como por ejemplo el poblado llamado La Tigra como elemento de esta fauna feroz, pues un habitante de ese pueblo había valientemente matado a una tigra y por ello le pusieron ese apelativo al lugar. Asimismo, hay nombres de pueblos que responden a elementos de la flora existente en Upala, la designación del distrito Yolillal -en el norte del cantón- se debe al ecosistema tropical de las costas lacustres, inundado y dominado por el yolillo, que es una palma-Raphia taedigera-abundante en la zona, con cuyas hojas techan algunas viviendas y chozas. ${ }^{61}$

Hoy día, se mantienen algunos nombres de las antiguas fincas o haciendas, como finca Azul. También las colonias tienen referentes a la procedencia de los inmigrantes, por ejemplo, Colonia Blanca pues muchos de sus pobladores venían de Liberia, llamada la ciudad blanca por el color de sus tierras. Otra es la Colonia Libertad, designada así en honor al expresidente José Figueres Ferrer al salir victorioso en la guerra civil de 1948.

La población en la frontera norte ha construido un apego al territorio por el abandono que tuvo de parte del Estado nacional, muchas veces se habla de una identidad de frontera, donde se han utilizado ambas monedas, se han compartido vocabulario y actividades económicas. Además, como zona de frontera se ha producido

59 AFR., A.C. Tomo XVI: 88.

60 Miguel Ángel Quesada Pacheco, “Toponimia indígena de Costa Rica", Revista de Filología y Lingüística de la Universidad de Costa Rica (Costa Rica) 32, n. 2 (2006): 251, DOI: https://doi.org/10.15517/rfl. v32i2.4297.

61 Véase: http://espores.org/index.php?option=com_k2\&view=item\&id=217\%253Aarticle-investigaci\%25 $\mathrm{C} 3 \% 25 \mathrm{~B} 3$ \& Itemid $=6$ \&lang $=$ es. 
el traslado ilegal de mercaderías y de personas. Es muy frecuente que los habitantes de ambos lados hayan compartido la historia, las experiencias y las leyendas.

De esta manera, a los nicaragüenses y a los costarricenses sin documentos no les interesaba nacionalizarse antes de 1950, y no hemos encontrado en sus autobiografías ese deseo. Su vida giraba alrededor de Upala y San Carlos de Nicaragua. Más bien, en el Valle Central de Costa Rica, a mediados del siglo $\mathrm{XX}$, la visión de aquella población fronteriza era la de un mundo de extranjeros, o sea, de nicaragüenses y de alguna manera, el Estado costarricense debía nacionalizarlos. La Municipalidad de Grecia había enviado a la Gobernación una carta solicitando la nacionalización por medio de una nueva ley de los distritos de Upala, Los Chiles y Guatuso. Sin embargo, los procedimientos chocaban con la Constitución Política y la Ley de Extranjería.$^{62}$ No fue hasta 1958 cuando se leía en el periódico La Nación: "Efectiva nacionalización de la Frontera Norte". ${ }^{63}$

Los territorios a lo largo de la frontera han estado unidos por vínculos sociales y comerciales. El intercambio de bienes y servicios entre uno y otro lado ha sido desigual debido al desarrollo social de los estados nacionales. Por un lado, Upala comparte más sus servicios educativos, de salud y de trabajo que Nicaragua, donde aquellos son muy precarios. Algunas familias comparten a sus miembros en ambos países y se visitan de vez en cuando. Durante muchas décadas, costarricenses y nicaragüenses estaban unidos por la solidaridad, una convivencia robusta basada en la reciprocidad y sentimientos de inclusión en ambos lados de la frontera.

Mientras las redes de comunicación y transporte solo estaban enfocadas hacia Nicaragua antes de 1970, los comerciantes se transportaron a través del río San Juan, y las lanchas eran un utensilio fundamental. Este trabajo era pesado y peligroso, para realizar los viajes había que desvelarse y asolearse, algunos pobladores dejaban esta actividad al encontrar una tierra para trabajar. Por ello, los primeros lazos comerciales se establecieron con Nicaragua ya que Upala no tenía comunicación con el resto de las regiones de Costa Rica. Del otro lado de la frontera, la ciudad-puerto eje de las relaciones comerciales y religiosas fue San Carlos de Nicaragua.

Todavía en la década de 1970, la búsqueda de tierra apta para cultivar en baldíos de ambos países era regular. Se ha tenido más información sobre migrantes nacionales en la exploración de suelo para ocuparlo; pero también, era a la inversa, como lo leeremos en la siguiente autobiografía:

“[...] conversando con unos compañeros respecto a unos terrenos valdíos que hay a la orilla del lago, en la desembocadura del río Zapote, en territorio de Nicaragua.

Resolvimos hacer un viaje y así fletamos un bote por quinientos colones entre cuatro,

62 Diario de Costa Rica, "Sería nula la ley para nacionalizar a los habitantes de la Zona Norte. Upala", 15 de junio de 1951, 8. La Nación, "Los Chiles y Upala requieren oficina para naturalización de extranjeros", 14 de octubre de 1956. Se agradece al Msc. Maximiliano López López por el acceso a esta información periodística.

63 La Nación, "Efectiva nacionalización de la Frontera Norte", 7 de julio de 1958. 
pero luego se nos arrimaron tres jóvenes norteamericanos del cuerpo de paz, que querían conocer territorio nicaragüense [...] llegamos a una parte que llaman Yolilla, y donde el río se riega por todo el terreno quedando luego un pequeño canal; $[\ldots]$ hasta que salimos de nuevo a lo limpio donde el río se hace más grande porque es una entrada del lago; pero ahí si es una paisaje maravilloso, donde las aves marinas revolotean y pescados de todas clases se ven a la orilla del bote, sobresaliendo los sábalos por su gran tamaño más de un metro y los gaspares que abundan [...]" ${ }^{64}$

Todo indica que no era difícil sembrar en terrenos nicaragüenses, pues el mismo campesino escribía que era una zona privilegiada para todo lo que se siembre y el gobierno de Nicaragua extendía títulos suplementarios y daba ayuda con bancos de allá para que se habilitaran esas zonas.

Al final de la década de 1950, la Dirección General de Estadísticas y Censos realizó un mapeo censal del antiguo distrito de Upala, podemos observar que ya se encontraba establecida como comunidad porque poseía una organización, por medio de la Junta de Educación, la Junta Progresista y la Junta Rural del Banco Nacional de Costa Rica. Además, el distrito tenía ya pulperías, hoteles, la Iglesia católica y otras más construcciones:

\section{Mapa 4 \\ Distrito de Upala: plano de la villa central (1959)}

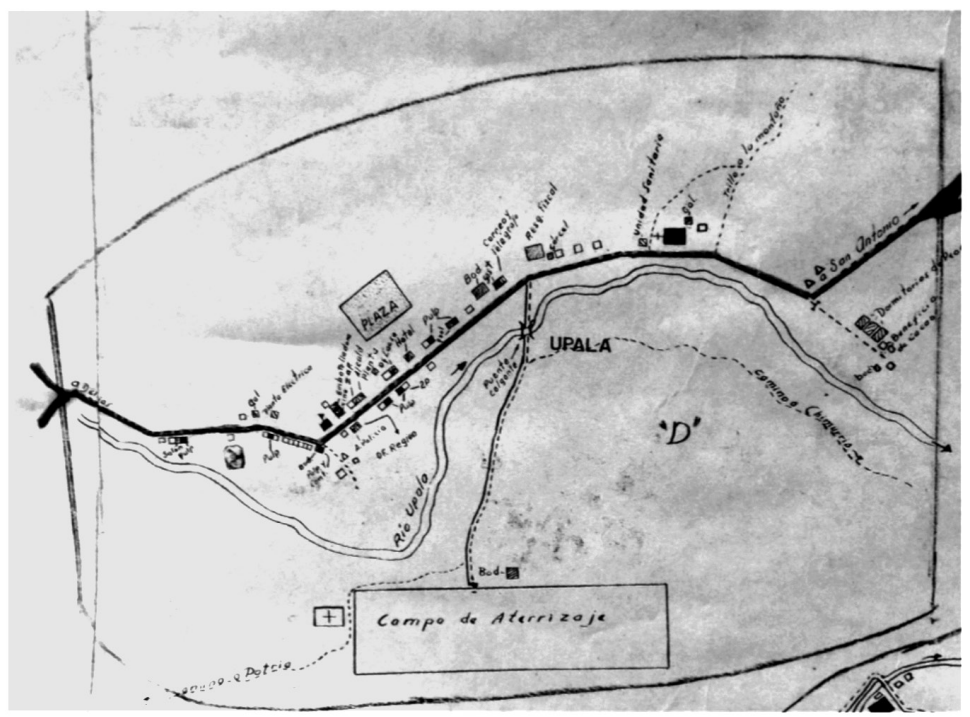

Fuente: DGEC, Planos censales. Distrito de Upala (San José, Costa Rica: DGEC, 1959).

64 A.F.R., A.C. Tomo XVI: 92. 
Diez años después, en el centro de Upala había organizaciones de carácter más social como eran los alcohólicos anónimos. A.F.R. dedicó parte de su autobiografía a describir la conformación de esta organización y las actividades y enlaces con alcohólicos anónimos de otras zonas, incluso fuera del país. Dentro de la sociedad llegaron a tomar fuerza otros proyectos comunitarios:

\begin{abstract}
"la comunidad, nos prestó ayuda: La Asociación de desarrollo el Salón de la municipalidad las instalaciones eléctricas, pues llevé mi planta, y la junta de educación nos prestó el mobiliario y los trastes de cocina de la escuela. Nos visitó el delegado Cantonal, y nos prestó la guardia para celar el orden, el médico, el sacerdote y personas importantes de la comunidad, ya que el señor alcalde es alcohólico anónimo y varios profesores y el director de la escuela". ${ }^{65}$
\end{abstract}

Las personas estaban apegadas a las organizaciones comunales, varios de los pobladores mencionaron que trabajaban en estas porque se fueron construyendo lazos de colectividad, a pesar de las continuas migraciones internas y externas. Nicaragüenses y costarricenses compartieron como población transfronteriza varios factores: la religión católica en su mayoría, vocablos lingüísticos, costumbres y actividades en las fiestas patronales de un lado o del otro, el uso de las vías fluviales, la toponimia y el uso de córdobas primero y luego el colón a ambos lados de la frontera.

Estos pobladores de Upala vivían en la periferia geográfica y cultural del centro nacionalista en ambos países. En Nicaragua, la imagen de sus habitantes reflejaba al nicaragüense del Pacífico, tal como lo describe Pablo Cuadra en su libro El nicaragüense de 1967; ${ }^{66}$ y en Costa Rica, Constantino Láscaris describió al costarricense del Valle Central en su obra Los costarricenses en 1962. ${ }^{67}$ Estos imaginarios se fueron neutralizando por la lejanía de estas poblaciones con las capitales y el desapego del Estado en construir vías de comunicación y en desarrollar los territorios en las fronteras. Las identidades en estos habitantes se fundamentaron más bien en lo que tenían en común, tal como la etnia, los grupos etarios, aspectos culturales, religiosos, comerciales y de género. Compartieron aquella soledad y un mundo natural que ofrecía a veces retos y a veces oportunidades.

Es interesante que solo en una de las autobiografías se refleja cómo los pobladores del norte se relacionaron con las zonas del sur de Nicaragua y pareciera que no había una división importante en las redes de comunicación o familiares, pero esto no aplicaba para todos los pobladores, pues aquellos que llegaron de otras zonas del país y más si fueron a la escuela como el caso de H.R.S.,

65 A.F.R., A.C. Tomo XVI: 94.

66 El Nuevo Diario, "El nicaragüense, de PAC: una relectura", 1 de octubre de 2011, URL: https://www. elnuevodiario.com.ni/opinion/115441-nicaraguense-pac-relectura/.

67 Constantino Láscaris Comneno, El costarricense (San José, Costa Rica: EDUCA, 1975). 
su posición nacionalista era tan fuerte que se casó con una mujer costarricense, identificándose como "Nosotros los Campesinos Costarricenses" para referirse a que deben estar juntos. ${ }^{68}$ Este campesino había nacido en Villa Quesada, San Carlos, en 1924. Sus raíces familiares se encontraban en la cabecera de ese cantón. Este poblador mantenía una posición nacionalista, pues sugiere en varias ocasiones la palabra Costa Rica o costarricense, seguramente estaba haciendo una división entre los costarricenses y los nicaragüenses, a pesar de que en la zona interactuaban pobladores de ambas nacionalidades con sus redes comerciales y familiares.

También relaciona al campesino costarricense con la pequeña propiedad, mito que se estableció desde la Colonia:

\footnotetext{
"Había llegado el momento de efectuarse una boda más entre Nosotros los Campesinos Costarricenses, quienes también somos dueños de este pedacito de Tierra Bendita y Gloriosa, que Dios nos ha dado, en quien el Mundo entero a puesto sus ojos, Mirando en el Mayor halago su belleza, y diversas riquezas, y hospitalidad". ${ }^{9}$
}

\section{Conclusiones}

De acuerdo con el origen de los inmigrantes, en el norte del cantón se encontraba más población nicaragüense que en el resto, sus pobladores llegaron por la única vía de transporte y comunicación que fueron los ríos Zapote y Pizote o Niño. Solo algunos lograron entrar marcando trocha por México de Las Delicias de Upala. Los habitantes de la línea fronteriza son poblaciones que se identifican más con sus orígenes nicaragüenses, aunque al preguntar sobre su identidad individual, la mayoría se siente costarricense. Puede ser por los servicios que brinda el Estado costarricense a las poblaciones transfronterizas, de igual manera se reproduce este patrón en otros cantones que limitan con Nicaragua.

No hemos encontrado en las autobiografías ni en las entrevistas realizadas en el proyecto situaciones que evidencien muros materiales o imaginarios en los pobladores antiguos de Upala, mayores de cincuenta años. Vale decir que, el puesto fronterizo de Costa Rica en Upala no ha estado ejerciendo funciones, pero, en el borde nicaragüense hay construido un edificio amplio y existen distintos funcionarios y militares armados custodiando la frontera. Más bien, la entrada de nicaragüenses temporales o no se da en forma fluida. Sin embargo, la frontera norte fue estratégica para la política militar de Nicaragua y Costa Rica en el decenio de 1970 y luego de los Estados Unidos en la

68 H.R.S., A.C. Tomo XVI: 39.

69 Ibid. 
década de 1980. A pesar de ello ha habido una estrecha relación entre las comunidades transfronterizas. ${ }^{70}$

Los inmigrantes costarricenses arribaron a ese territorio bordeando la cordillera de Guanacaste, ya sea por las hondonadas entre el volcán Tenorio y el Miravalles o entre este y el Rincón de la Vieja. Algunos otros, de La Cruz de Guanacaste, llegaron a Upala por vía de Santa Cecilia; colonizaron la parte norte de Dos Ríos y San José hasta el límite geográfico del río Pizote o Niño. En estas zonas hay una mayor vinculación con Guanacaste que con Alajuela, provincia donde se encuentra Upala. En los últimos años, Upala ha perdido población por la falta de trabajo, en especial los adolescentes que terminan el colegio y los que asisten a las universidades en Guanacaste o en el Valle Central. ${ }^{71}$

Después de la construcción de la carretera de Upala a Cañas, el camino a Bagaces y a Santa Cecilia de La Cruz, todos de Guanacaste, y de Los Chiles y Guatuso a San Carlos de Alajuela, los habitantes en Upala y pobladores de la zona fronteriza han tenido la oportunidad de comunicarse mejor con Guanacaste y Alajuela, y de esta manera, si antes el córdoba era la moneda del lugar, hoy fluye más el colón. Las rutas en Nicaragua para llegar a Upala son difíciles, por el lago y los ríos que ya no tienen la capacidad de trasladar tanto peso en carga y en personas. Para los nicaragüenses es preferible tener relaciones comerciales con Upala que con Managua o el antiguo puerto de San Carlos y además los servicios públicos costarricenses son más amplios que los de esa zona nicaragüense. A manera de conclusión, transcribo este párrafo de la revista Envío:

\begin{abstract}
"Muchos habitantes de Papaturro dicen: Nosotros queremos ser de Costa Rica. La Alcaldía no hace nada por Nicaragua. Si no son capaces aquí, que hagan acuerdos con el otro lado. Porque la pobre gente de aquí no tiene nada. El casi hermanamiento con el municipio costarricense de Upala los salvó de que los estudiantes perdieran este año escolar. Upala los quiere conectar a su tendido eléctrico. Upala les lleva odontólogos con medicamentos gratuitos. Por eso es comprensible que una madre en Papaturro proteste: Cómo vamos a creer que nos consideran parte del país si nos quitaron al médico y al profesor, que además se pasaba el tiempo en San Carlos. Ahora nuestros niños van a ir a Costa Rica y nunca más vamos a volver a matricularlos en una escuela nicaragüense. Sólo cuando hay campaña electoral nos utilizan y el resto del tiempo nos tienen olvidados". ${ }^{72}$
\end{abstract}

70 Melba Mora Rojas y Guiselle Román López, "Fronteras: muros imaginarios, muros materiales y muros virtuales. Los Chiles, en la frontera norte de Costa Rica. Un estudio de caso", Ístmica. Revista de la Facultad de Filosofia y Letras de la Universidad Nacional (Costa Rica) 15 (2012): 39-51, URL: http:// www.revistas.una.ac.cr/index.php/istmica/article/view/6006.

71 No hay diferencia hoy en la tasa de desempleo al comparar costarricenses y nicaragüenses. Delgado y Córdoba, 13.

72 José Luis Rocha, "Queremos ser de Costa Rica", Envío Digital, 308 (noviembre, 2007), URL: http://www. envio.org.ni/articulo/3667. 